\title{
Studies on Properties of Egg Shell and Fish Bone Powder Filled Polypropylene
}

\author{
Isaac O. Igwe*, Genevive C. Onuegbu
}

Department of Polymer and Textile Engineering, Federal University of Technology, Owerri, Nigeria

\begin{abstract}
The mechanical and end-use properties of egg shell and fish bone powder filled polypropylene have been determined at filler contents, 0 to $40 \mathrm{wt}$ \%, and particle sizes, $0.150,0.30$, and $0.420 \mu \mathrm{m}$. Talc, of particle size, $0.150 \mu \mathrm{m}$ was used as the reference filler. The incorporation of egg shell and fish bone powder into polypropylene resulted in improvement in the tensile strength, tensile modulus, flexural, and impact strength of the composites, and these properties increased with increase in filler contents, and decrease in filler particle sizes. The elongation at break of the composites was observed to decrease with increase in filler contents, and particle sizes. The hardness, specific gravity, and water absorption ( $24 \mathrm{~h})$ of the prepared composites were found to increase with increase in filler contents, and decease in filler particle size. Talc filled polypropylene was observed to absorb less water than fish bone or egg shell powder filled polypropylene. The amount of water absorbed by these composites was observed to be independent of filler content or particle size but on the nature of the filler used. The fillers under investigation efficiently reduced the rate of burning of polypropylene at high filler contents, and particle sizes. Generally, egg shell, and fish bone powder fillers have shown greater property improvement over talc in the prepared composites. Egg shell, and fish bone powder fillers could be viable alternatives to the conventional mineral fillers for the plastic industry, and for applications where the high water absorption of the fillers is not a critical factor of interest.
\end{abstract}

Keywords Polypropylene, Composite, Mechanical and End-Use Properties, Filler, Egg Shell and Fish Bone Powder, Filler Particle Size, Talc

\section{Introduction}

Polypropylene is one of the most important polyolefins that have a wide range of applications. The use of filled polypropylene in electrical and automotive engineering is presently on the increase due to its excellent stiffness property. Like any other polyolefin, polypropylene is widely exploited but not used as a neat polymer. To enhance the properties of polyolefins, they are frequently compounded with natural minerals (fillers).

Fillers which merely increase the bulk volume and hence, reduce price, are known as extender fillers while those which improve mechanical properties, particularly tensile strength are termed as reinforcing fillers[1]. Several million metric tons of fillers and reinforcements are used annually by the plastic industry. The use of these addictives in plastics is likely to grow with the introduction of improved compounding agents that permit the use of high filler/ reinforcement content[2]. It has been suggested that fillings up to 75 parts per hundred (pph) could be a common practice in future, and that this level of filler addition could have a

* Corresponding author:

izikigwe@yahoo.com (Isaac O. Igwe)

Published online at http://journal.sapub.org/ajps

Copyright (C) 2012 Scientific \& Academic Publishing. All Rights Reserved tremendous impact in lowering the usage of petroleum-based plastics. Filler particles form aggregates or agglomerates with increasing volume fraction and this depends on their surface energy, and area. The mechanism of polymer reinforcement by fillers is not yet fully understood, and is the subject of many publications in the scientific literature[3-5]. Generally, the properties of filled polymers change with the dispersion state, geometrical shape, and surface quality of the filler particles as well as the particle size.

The outlook for filled polypropylene is becoming brighter due to the recent commercial availability of nanosized fillers. Nanocomposite materials with length scales smaller than $1 \mu \mathrm{m}$ are becoming important as the size of modern electronic devices reaches down to the submicron scales. Typical fillers for polypropylene are glass fibres, glass sphere, talc, asbestors, silica, and mica. The use of mineral fillers and fibres in making polymer composites has its disadvantages. For example, a lot of energy is used in the processing of glass fibres since their processing temperatures can exceed $1200^{\circ} \mathrm{C}$. Also, glass fibres tend to abrade processing equipments, and increase the density of the plastic system[6].

In the literature, different materials have been studied to fill polypropylene. These materials include saw dust[7], wood flour[8], flax fibre[9], hemp strands[10], flax pulps [11], lyocell fibre[12], green-coconut fibre[13], montmorillonite[14,15], calcium carbonate[16,17], magnesium hy- 
droxide[18], and snail shell powder[19].

Recently, Yunus et al[20] prepared carbon fibre - polypropylene composites under various process conditions, and determined the mechanical properties of the prepared composites. The highest tensile strength was obtained for polypropylene (MFI 60) composites reinforced with 10 wt.\% carbon fibre. The composites also exhibited the best tensile, and flexural properties. Also, Wang et al [21] prepared nano- $\mathrm{CaCO}_{3} /$ homo - polypropylene composites by melt blending using twin - screw extruder. The results showed that both the impact property and bending modulus of the composites were evidently increased on addition of nano- $\mathrm{CaCO}_{3}$. The electron-beam preirradiation and reactive extrusion technologies were used to prepare maleic anhydride (MAH)/ vinyltrimethoxysilane (VTMS) -co-grafting polypropylene(PP) as a high-performance compatibilizer for wood-flour/PP composites [22]. The experimental results demonstrated that MAH/VTMS-g-PP markedly enhanced the mechanical properties of the composites. Compared with MAH-g-PP and VTMS-g-PP, MAH/VTMS-g-PP clearly showed synergistic effects on increasing the mechanical properties, water absorption, and compatibility of the composites.

The use of egg shell powder to fill polypropylene has also been reported[20]. Polypropylene composites of egg shell powder were prepared at filler contents, 0 to $5 \mathrm{wt} \%$, and particle size, $0.30 \mu \mathrm{m}$. The properties of the composites determined were the specific gravity, water sorption (24 h), flammability rate, and hardness tests.

In the present report, the effects of incorporating egg shell (ESP), and fish bone powder (FBP) as fillers on the mechanical and end-use properties of polypropylene were studied. The central objectives are to (i), investigate fully the properties of polypropylene composites of egg shell and fish bone powder, and (ii), determine the effects of egg shell, and fish bone powder particles sizes on the properties of polypropylene composites. Filler contents of 0 to $40 \mathrm{wt}$. \% were used in this study. It is important to note that the work reported on the utilization of egg shell powder to fill polypropylene[23] was exploratory and limited in scope.

Egg shell and fish bone are domestic wastes and could be found littering dustbins in our big cities, and farm yards in villages. Besides the work reported above on egg shell powder[23] which was exploratory and limited in scope, the use of egg shell or fish bone to fill polypropylene or any other thermoplastic has not been reported in the scientific literature to our knowledge.

\section{Materials and Methods}

\subsection{Materials}

The polypropylene used in this study was obtained from Eleme Petrochemical Company Limited, Rivers State, Nigeria. It has a melt flow index of 2.5 to $3.5 \mathrm{~g} / \mathrm{min}$, and density, $0.926 \mathrm{~g} / \mathrm{cm}^{3}$. The egg shell, and fish bone from which egg shell, and fish bone powder were produced were collected locally within Owerri Metropolis, Imo State, Nigeria. These materials were properly treated to remove impurities before they were crushed and sieved to three particles sizes namely, $0.150,0.30$, and $0.42 \mu \mathrm{m}$. Talc, which was used as the reference filler was purchased from a local store at Owerri, Imo State, Nigeria.

\subsection{Preparation of Polypropylene Composites}

The polypropylene composites of egg shell (ESP), and fish bone powder (FBP) were prepared as described previously for snail shell powder composites of polypropylene [23]. The polypropylene composites of talc were prepared only at filler particles size, $0.150 \mu \mathrm{m}$.

\subsection{Testings}

Testings on the mechanical and end-use properties of polypropylene composites were carried out as described previously using standard procedures[23].

\section{Results and Discussion}

\subsection{Mechanical Properties}

\subsubsection{Tensile Strength}

The effects of egg shell and fish bone powder contents, and particles sizes on the tensile strength of polypropylene are illustrated in Figure 1. From Figure 1, it is evident that the tensile strength of polypropylene composites increased with increase in egg shell, and fish bone powder contents. Onuegbu and Igwe[19] who studied snail shell powder/ polypropylene system reported increases in tensile strength of polypropylene with increase in snail shell powder content. Figure 1 shows that the tensile strength of egg shell, and fish bone powder filled polypropylene was higher than that of talc filled polypropylene at filler particle size, $0.150 \mu \mathrm{m}$. Figure 1 also shows that the smaller the particle size of the filler, the higher the tensile strength of polypropylene composites. The envisaged better dispersion of the smaller sized filler in the polypropylene matrix, and improved filler-matrix interaction may be the factors responsible for the observed trend. Similar observations on the variation of composite strength with filler particle size have been reported by Bigg [24], and Fuad et al [25] for other filled polymer systems.

At any particle size of the fillers investigated, the order in the improvement of tensile strength of polypropylene composites is fish bone $>$ egg shell powder.

\subsubsection{Tensile Modulus}

The tensile modulus of filled and unfilled polypropylene are illustrated in Figure 2. Figure 2 shows that the modulus of polypropylene composites were higher than the modulus of unfilled polypropylene, and increased with increase in filler content. This observation highlights the fact that the incorporation of fillers into polymer matrix improves the stiffness 
of the latter. The result obtained in this study is in agreement with the findings of Rozman et al[26] who working on oil palm empty fruit bunch powder - polypropylene system found that the tensile modulus of polyethylene composites increased with increase in oil palm empty fruit bunch powder content. Similarly, Onuegbu and Igwe[19] had reported an increase in tensile modulus of polypropylene on addition of snail shell powder. Both egg shell, and fish bone powder enhanced the tensile modulus of polypropylene more than talc, the reference filler (Figure1). However, fish bone powder was superior to egg shell powder in increasing the tensile modulus of polypropylene.

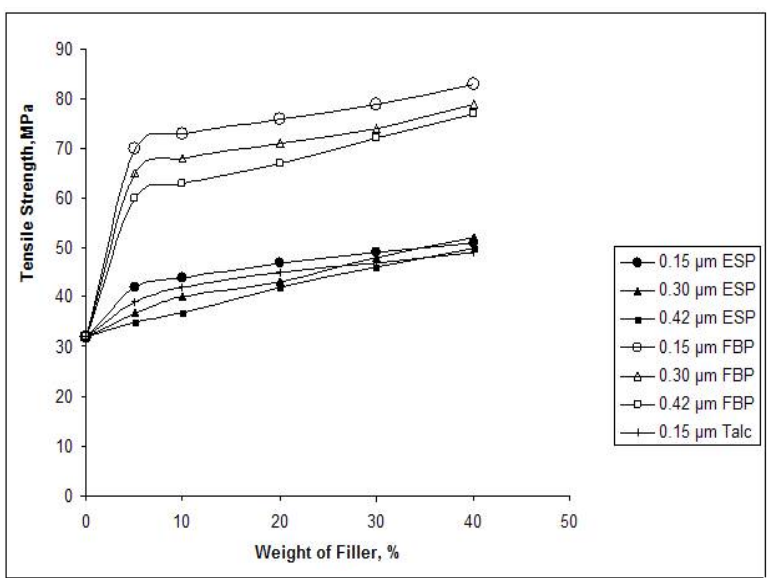

Figure 1. Plot of Tensile Strength versus Weight of Filler for Polypropylene Composites at different Filler Particle Sizes

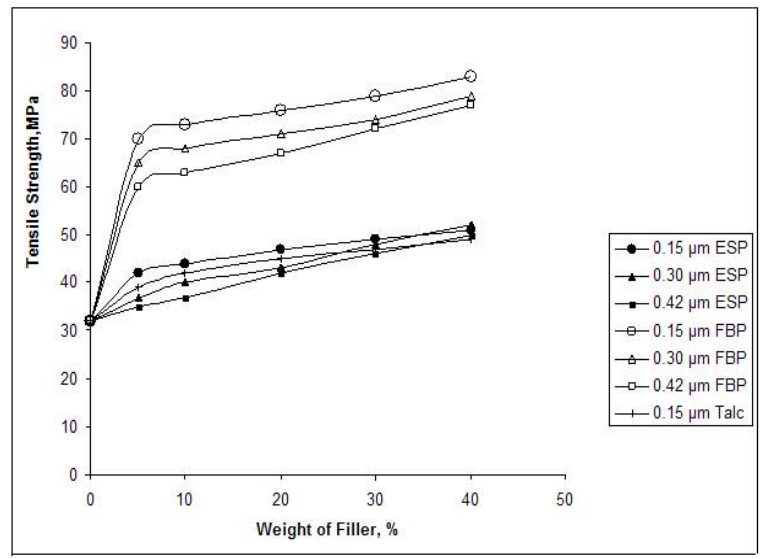

Figure 2. Plot of Tensile Modulus versus Weight of Filler for Polypropylene Composites at different Filler Particle Sizes

\subsubsection{Flexural Strength}

The experimental data on the flexural strength of polypropylene composites are illustrated graphically in Figure 3. It is evident that at any particle size of the fillers considered, the flexural strength of the composites increased with increase in filler contents. Figure 3 also shows a general decrease of flexural strength of the composites as the particle size of the fillers increased from 0.150 to $0.420 \mu \mathrm{m}$. Similar decrease in material property with increase in filler particle size was also observed for the tensile strength and tensile modulus of the composites. The general order in the en- hancement of the flexural strength of polypropylene composites is fish bone $>$ egg shell powder, and at $0.150 \mu \mathrm{m}$ filler particle size considered, the order is fish bone powder $>$ egg shell powder $>$ talc. This order shows that egg shell, and fish bone powder are better fillers than talc in enhancing the flexural strength of polypropylene.

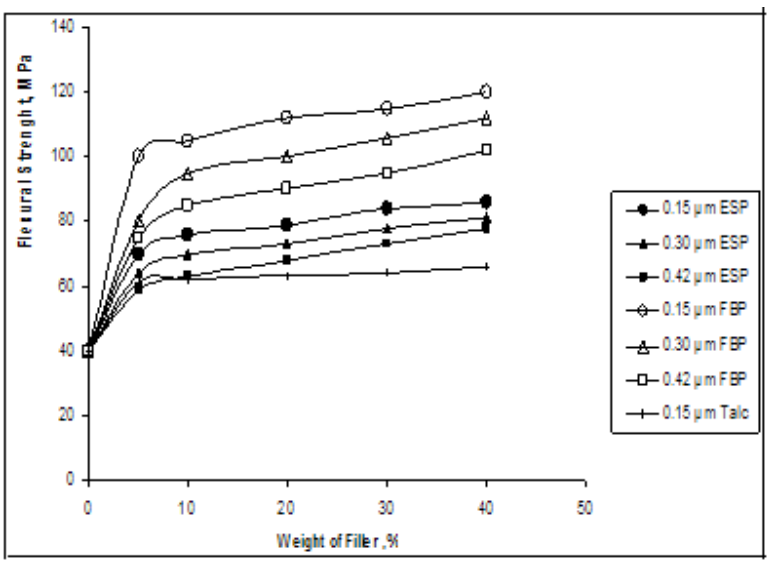

Figure 3. Plot of Flexural Strength versus Weight of Filler for Polypropylene Composites at different Filler Particle Sizes

\subsubsection{Elongation at Break}

Elongation at break (EB) is a measure of the ductility of a material. The data on elongation at break obtained for polypropylene composites at different filler contents, and particle sizes are illustrated graphically in Figure 4. The figure shows that the EB of polypropylene composites decreased with increase in the filler contents at any filler particle size considered. Fillers, generally can be considered as structural elements embedded in the polymer matrix, and at the concentrations of the fillers used ( 0 to $40 \mathrm{wt}$. \%), the concentrations might not be high enough to significantly restrain the polypropylene molecules. Consequently, highly localized strains might have occurred at the concentrations investigated, causing dewetting between polypropylene and the fillers, and thus, leaving essentially a matrix that is not ductile. Such a reduction in elongation at break of polypropylene composites on addition of fillers has been reported by Onuegbu and Igwe[19], Fuad et al[25], and Basuki et al[27].

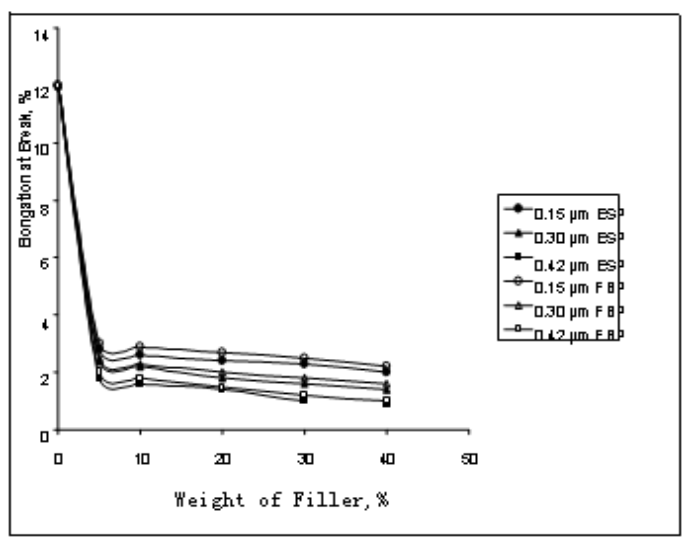

Figure 4. Plot of Elongation at Break versus Weight of Filler for Polypropylene Composites at different Filler Particle Sizes 
It is important to note that the EB of polypropylene composites decreased with increase in filler particle size. Firstly, there is the envisaged better dispersion of the smaller sized fillers which reduced the tendency of filler - matrix interaction from taking place. Thus, the samples can be elongated to a much higher value. However, at the highest filler content investigated (40.0 wt. \%), the degree of filler matrix interactions might have become more prominent even in the case of composites of smaller sized filler. Consequently, dramatic reduction in EB was observed. Secondly, the interface needs to be considered. The increment in filler contents will eventually result in a reduction of the deformability of a rigid interface between the fillers, and polypropylene matrix. Talc filled polypropylene did not show any elongation at break, an indication of the brittle nature of the composites.

\subsubsection{Impact Strength}

The data on impact strength of the polypropylene composites are illustrated graphically in Figure 5. The figure shows that the impact strength of polypropylene composites increased with increase in filler content at any filler particle size considered. Such an increase in impact strength of a thermoplastic composite with increase in filler content has been reported in the literature[23,28]. The impact strength of the composites was observed to decrease with increase in filler particle size for any filler content considered. Thus, increasing the particle size of the fillers at a given filler content probably increased the level of stress concentration in the composites with the resultant decrease in impact strength. However, Guo et al[16] who investigated polypropylene/carbonate system found that the impact strength of the composites increased at first with increase in filler content, and later, decreased with further addition of fillers.

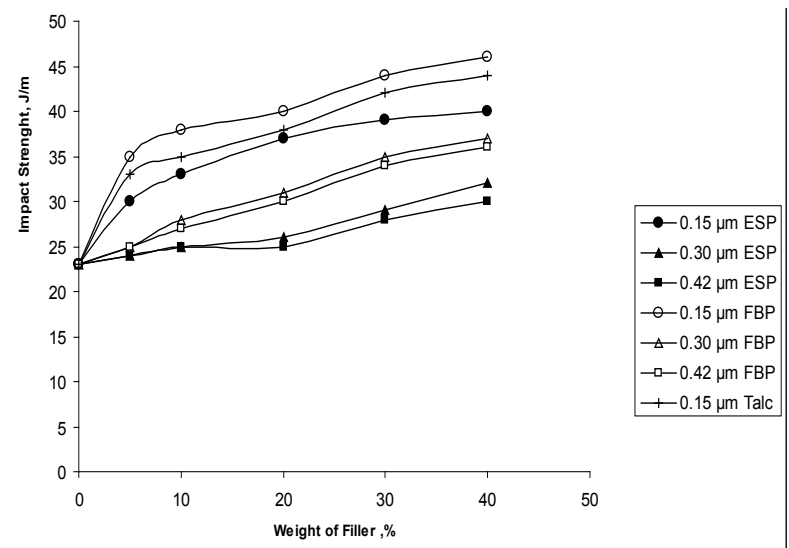

Figure 5. Plot of Impact strength versus Weight of Filler for Polypropylene Composites at different Filler Particle Sizes

Figure 5 shows that when talc is used to make the composites, the order in enhancing the impact strength of polypropylene is fish bone $>$ talc $>$ egg shell powder. However, for a given filler particle size, the order is fish bone $>$ egg shell powder.

\subsection{End-Use Properties}

\subsubsection{Hardness}

Figure 6 shows the effect of filler contents and particle sizes on the hardness of filled polypropylene. The hardness of unfilled polypropylene is $22.0 \mathrm{MPa}$. The figure shows that the hardness of all filled polypropylene at a given filler particle size increased with increase in filler content. This result indicates enhancement of abrasion and impact strength of the composites. For a reinforcing filler, the composite becomes stiffer and harder with increase in filler content. Such increases in composites hardness with increase in filler content have been reported by Chakraborty et al[29], and Igwe and Njoku[30]. Generally, the hardness of all the composites decreased with increase in the filler particle size at any given filler content considered. At any given filler particle size considered, the order in the enhancement of hardness of polypropylene is egg shell $>$ fish bone powder, and when talc was incorporated into polypropylene, the observed order is egg shell $>$ fish bone powder $>$ talc.

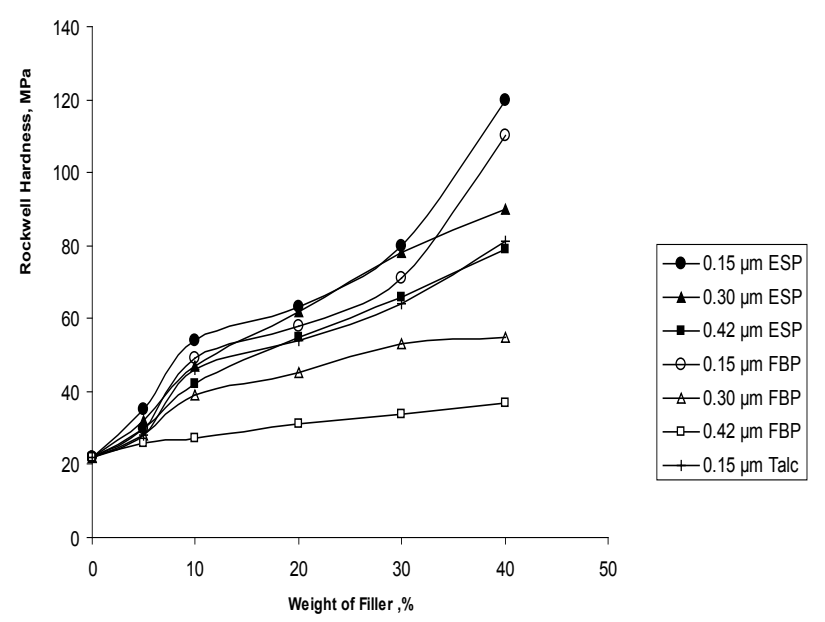

Figure 6. Plot of Rockwell Hardness versus Weight of Filler for Polypropylene Composites at different Filler Particle Sizes

\subsubsection{Water Sorption}

The variation of water absorbed by the composites with filler content at any given filler particle size is not much. Similarly, the amount of water absorbed by the composites at a given filler content varies slightly with the filler particle size. These observations are indications that the amount of water absorbed by polypropylene composites is not strongly dependent on the filler content or particle size but on the nature of filler used. Figure 7 shows that all the filled polypropylene absorbed more water than unfilled polypropylene. Fish bone powder composites of polypropylene were observed to absorb more water than those of egg shell powder. However, talc filled polypropylene absorbed less water than those of egg shell or fish bone powder. Bogoera-Gacera et al[31] who studied jute fibre filled polypropylene reported that the amount of water absorbed by the composites increased with increase in jute fibre content. Similar observations to ours in this study have also been reported by Ewulonu and Igwe[32] for oil palm fruit bunch fibre filled high density polypropylene. 


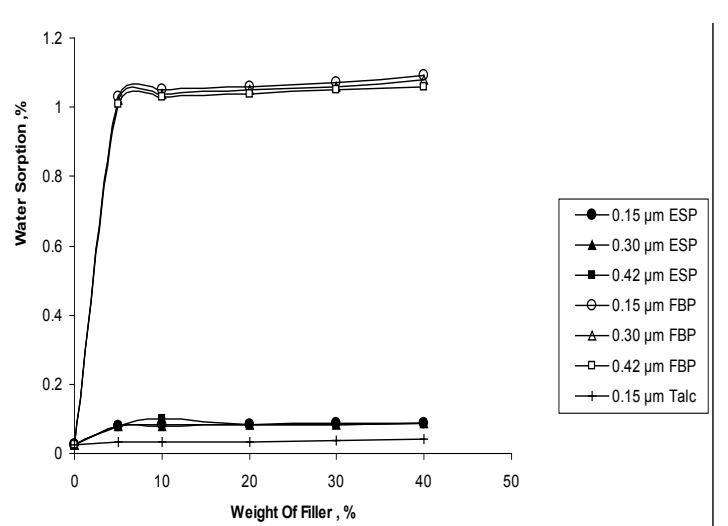

Figure 7. Plot of Water Sorption versus Weight of Filler for Polypropylene Composites at different Filler Particle Sizes

The level of water absorb by egg shell, and fish bone powder filled polypropylene is considerably higher than those for other mineral filled systems[6]. Water absorption is one of the important characteristics of composites that determine their end use applications. It can lead to a decrease in some of the composites properties, and therefore, needs to be considered when selecting applications for possible use of egg shell, and fish bone powder filled polypropylene.

\subsubsection{Specific Gravity}

Data on the specific gravity of the various filled polypropylene are illustrated graphically in Figure 8 . The specific gravity of unfilled polypropylene is 0.95 . Figured 8 shows that there was a general increase in the specific gravity of polypropylene composites in comparison to unfilled polypropylene at any given filler particle size considered. However, the specific gravity of the composites decreased with increase in the particle size of the fillers. The increase in the specific gravity with a reduction in the filler particle size could be attributed to the greater and more uniform dispersion of the smaller sized fillers in the polypropylene matrix. The general increase in the specific gravity of the prepared composites with increase in filler contents as was observed in this study is in general agreement with our earlier reports[19,32]. In this study, egg shell, and fish bone powder have shown greater increase in specific gravity over talc in the prepared composites.

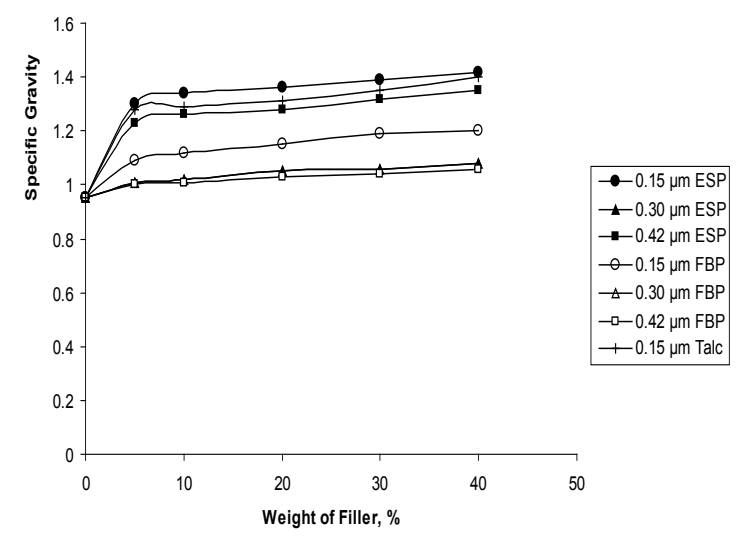

Figure 8. Plot of Specific Gravity versus Weight of Filler for Polypropylene Composites at different Filler Particle Sizes

\subsubsection{Flame Propagation}

Figure 9 shows that the rate of burning of the composites at any given filler particle size decreased with increase in filler contents. The burning behavior of polypropylene, a thermoplast, involves shrinkage and often, melting when subjected to heat. Both melting and shrinkage have the effect of reducing the apparent flammability of polypropylene. On approaching the ignition source, polypropylene shrinks, and even, drips away from the flame. This behavior ensures energy removal, decrease in surface area exposed, and hence, reduction in oxygen accessibility. The present flame retardant property of egg shell, and fish bone powder fillers investigated could be attributed also to their calcium carbonate contents among the other factors.

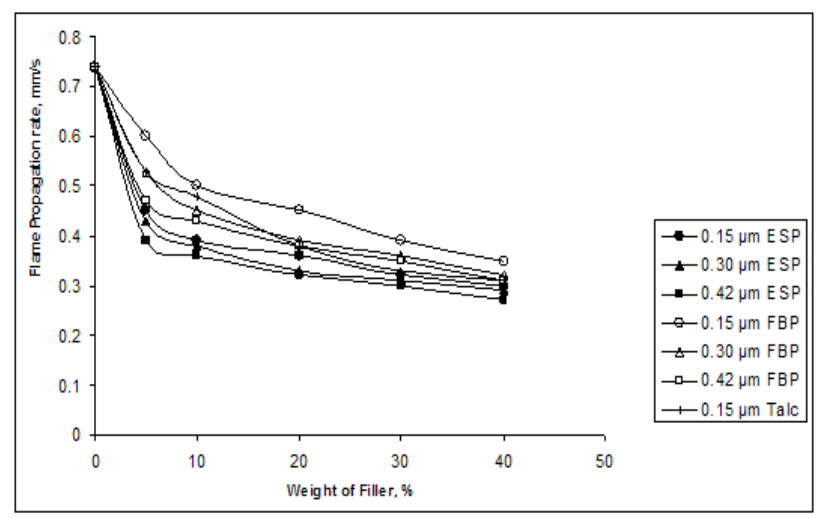

Figure 9. Plot of Flame Propagation Rate versus Weight of Filler for Polypropylene Composites at different Filler Particle Sizes

Both fish bone, and egg shell contain calcium carbonate $\left(\mathrm{CaCO}_{3}\right)[30,31]$. On the application of heat/flame, calcium carbonate decomposes according to the equation,

$$
\mathrm{CaCO}_{3} \stackrel{\Delta}{\longrightarrow} \mathrm{CaO}+\mathrm{CO}_{2}
$$

With the evolution of carbon dioxide $\left(\mathrm{CO}_{2}\right)$ which does not support combustion. The more the fillers are incorporated into polypropylene, the more the quantity of $\mathrm{CaCO}_{3}$ in the composites, and the less, the tendency of the composites to burn since $\mathrm{CO}_{2}$ is a good fire extinguisher. Another possible factor for the observed flame retardant property of the fillers could be the interaction of the fillers with polypropylene, the possible mechanism which has been described previously [19].

The effect of filler particle sizes on the flame retardant property of egg shell, and fish bone powder is not very apparent in this study since all the filler particle sizes investigated exhibited similar flame retardment property.

\section{Conclusions}

Egg shell, and fish bone powder have been utilized successfully in preparing polypropylene composites. The tensile strength, tensile modulus, flexural strength, impact strength, hardness, and specific gravity of the polypropylene composites were found to increase with increase in filler contents, and decrease in filler particle size. The elongation at break of 
the prepared composites decreased with increase in filler contents, and particle sizes. With the exception of talc filled polypropylene, all the polypropylene composites of fish bone, and egg shell powder investigated showed significant water absorption in a $24 \mathrm{~h}$ water absorption test, and the level of water absorbed was higher than that of unfilled polypropylene, and considerably higher than those of mineral filled systems. It is therefore very important to select applications where this level of water absorption by egg shell, and fish bone powder filled polypropylene is not a critical factor such as in electrical housing components. Generally, the fillers under investigations have shown greater property improvements over talc in the composites prepared.

The cost of egg shell, and fish bone powder fillers is less than that of the polypropylene matrix. Similarly, the cost of compounding is unlikely to be higher than that for the conventional mineral based components. The use of egg shell, and fish bone powder as fillers for the plastic industry will not only provide a renewable source of filler for the plastic industry but also generate a non - food source of economic development for the famers in the rural areas.

\section{REFERENCES}

[1] Sun L., Xiao M., Xiao P., Song J., Wang W., Zhang Y. and Gong K. (2001). Mat. Res. Soc. Symp. 661, KK5.14.1KK5.14.9 .

[2] Katz H.S. and Milewski J.V. (1987). Handbook of Fillers for Plastics. Van Nonstrand Reinhold, NY.

[3] Payne A.R. and Whittaker R.E. (1971). Rubber Chem. Technol. 44, 440.

[4] Leonov A.I. (1990). J. Rheol. 24, 1039.

[5] Donnet J.B. (1998). Rubber Chem. Technol. 71, 323.

[6] Sandi A.R., Caulfield D.F., Jacobson R.E. and Rowell R.M. (1999). In: Kenaf Properties, Processing and Products, Mississippi State University, Ag and Bio Engineering, Chapter 32, 381-392.

[7] Nafaji S.K., Hamidinia E. and Tajvidi M. (2006). J. Appl. Polym. Sci. 100, 3641-3645.

[8] Steckel V., Clemons C.M. and Thoemon H. (2007). J.Appl.Polym.Sci.103, 752 - 763.

[9] Moran J., Alvarez V., Petrucci R., Kenny J. and Vazquez A. (2007). J. Appl. Polym. Sci. 103,228 - 237.

[10] Mutje P., Vallejos M.E., Girones J., Vilaseca F., Lopez A., Lopez J.P. and Mendez J.A. (2006). J. Appl. Polym. Sci. 102, $833-840$.

[11] Retegi A., Arbelaiz A., Alvarez R., Llano-Ponte R., Labidi J. and Mondragon I. (2006). J.Appl. Polym. Sci. 102, 3438 3445 .
[12] Borja Y., Rie $\beta$ G. and Lederer K. (2006). J. Appl. Polym. Sci. $101,364-369$.

[13] Leblanc J.L., Furtado C.R.G., Leite M.C.A.M. and Visconte L.L.Y. (2006). J.Appl. Polym. Sci.102, 1922 - 1936.

[14] Fan Y., Lou J. and Shinozaki D.M. (2007). J. Appl. Polym. Sci. 103, $204-210$.

[15] Wenyi W., Xiaofei Z., Guoquan W. and Jianfeng C. (2006). J. Appl.Polym.Sci.100, 2875 - 2880.

[16] Guo T., Wang L., Zhang A. and Cai T. (2005). J. Appl. Polym. Sci. 97, $1154-1160$.

[17] Wang Q. and Qu J. (2006). Polym. International 55(11), 1330 $-1335$.

[18] Chang X., Yu J. and Guo S. (2006). J.Appl.Polym. Sci. 102, $4943-4951$.

[19] Onuegbu G.C. and Igwe I.O (2011). Mat.Sci.Appl. 2, 801 809

[20] Yunus R., Zahari N.H., Salleh M.A.M. and Norazowa I. (2011). Key Eng. Mats. $471-472,652-657$.

[21] Wang W., Wang G., Zeng X. and Chen J. (2010). J. Appl. Polym. Sci. 115 (2), 911 - 916.

[22] Guo L., Li B. and Wang H. (2011). J. Appl. Polym . Sci. 121(1), $402-409$.

[23] Igwe I.O. (2007). J.Res.Eng. 4(2), 8 - 12.

[24] Bigg D.M. (1987). J. Polym, Sci. Technol. 1(2), 58 - 62.

[25] Fuad M.Y.A., Ishmail Z., Ishak Z.A.M. and Omar A.K.M. (1995). Eur.Polym. J. 31(9), 885 - 893.

[26] Rozman H.D., Peng G.B. and Ishak. Z.A.M. (1999). J.Polym.Sci. 70 (13), 2647 - 2655.

[27] Basuki W., Purboro G. and Hanafi I. (2004). Int. J. Polym. Mat. 53(4), 295 - 306.

[28] Bigg D.M.(1987). Polym.Comp. 8(2), 115 - 122.

[29] Chakraborty S.K., Setua K.K. and De S.K. (1982). Rubber Chem. Technol. 55, 1286 - 1307.

[30] Igwe I.O. and Njoku C. (2008). Int. J. Phys. Sci. 3(4), 1- 6.

[31] Bogoera-Gaceva G., Dekanski, A., Panic V., Poleti D., Groz Danov A., Buzarovska A., Avella M. and Gentle G. (2006). Natural Fibres in Polymer Composite Materials, XLIV Meeting of the Serbian Chemical Society, Belgrade, February 6-7, $89-92$.

[32] Ewulonu C. M. and Igwe I.O. (2012). Int. J. Eng. Technol. $3(6), 458-471$.

[33] White A. (1954). Principles of Biochemistry, McGraw Book Co., New Delhi, 1162.

[34] http://www.serve.com/Baton Rouge/nutrition/egg shell.htm. 